\title{
Programme guidelines for promoting good oral health for children in Nigeria: a position paper
}

\author{
Morenike O Folayann ${ }^{1,2,3^{*}}$, Abiola A Adeniyi ${ }^{3,4+}$, Nneka M Chukwumah ${ }^{2,3 \dagger}$, Nneka Onyejaka ${ }^{2,3 \dagger}$, Ayodeji O Esan ${ }^{3,5 \dagger}$, \\ Oyinkan O Sofola ${ }^{3,6+}$ and Omolola O Orenuga $a^{3,7 \dagger}$
}

\begin{abstract}
Background: The objective of this paper is to draw attention to the oral health needs of children in Nigeria, and promote the use of appropriate interventions for disease prevention in the population. It also evaluates the value of the ongoing twice-daily tooth brushing campaign, which focuses on promoting good periodontal health and its relevance for children in Nigeria.

Discussion: The main oral health burden for children in Nigeria is untreated dental caries, attributable to low utilization of oral health facilities. While there is a strong association between oral hygiene status and caries occurrence, no research had established an association between frequency of tooth brushing and caries in children in Nigeria. Prevalence of caries and gingivitis is low, despite the fact that a majority of children brush once a day and most of them have fair oral hygiene. Campaigns that promote twice daily brushing to prevent chronic periodontitis in children are not driven by evidences supporting the local epidemic, and therefore cannot be considered as efficient use of the limited resources available.
\end{abstract}

Summary: Existing evidences show that the main oral health need of children in Nigeria is the management of untreated caries. Promoting the treatment of caries should be the primary focus of oral health programmes for children in Nigeria, as this would reduce further risks of developing new carious lesions. Public health campaigns should focus efforts at creating demand for oral health care services, for both preventive and curative purposes.

Keywords: Nigeria, Children, Caries, Campaign, Evidence, Oral health promotion

\section{Background}

The introduction of the National Oral Health Policy has fostered renewed interest in oral health in Nigeria. One group that has a potential to greatly benefit from the implementation of the policy is the school aged child. Policies often address the needs of school-aged children, since early interventions could help establish positive oral health behaviours, because attitudes towards oral health and oral disease patterns are often established in childhood [1-3].

One of the measures adopted for preventing oral diseases in children in Nigeria is the conduct of school screening exercises, as well as school based oral health

\footnotetext{
*Correspondence: toyinukpong@yahoo.co.uk

${ }^{\dagger}$ Equal contributors

'Department of Child Dental Health, Obafemi Awolowo University, Ile-lfe, Nigeria ${ }^{2}$ Department of Child Dental Health, Obafemi Awolowo University Teaching Hospitals Complex, lle-lfe, Nigeria

Full list of author information is available at the end of the article
}

education. An example was documented in the report by Sofola et al. [4]. Despite the ethical challenges associated with conducting disease screening exercises $[5,6]$, the conduct of school screening and school based oral health education programmes in Nigeria has its advantages. One of such is that it helps with the prompt diagnosis and referral of children with oral lesions for management. Past studies in Nigeria [4,7] showed that these referrals increased dental visits by children, howbeit for curative purposes. Oral health campaigns can reinforce the screening and oral health education processes. It is therefore important that any oral health campaign for children in Nigeria is effective, efficient and designed to achieve results relevant to the Nigerian context.

A national campaign to promote twice-daily tooth brushing among school children in Nigeria was recently introduced because of the need to reduce plaque accumulation and prevent periodontal diseases. This was based largely on the link between periodontal health and heart disease $[8,9]$. 
There are a number of issues raised by this campaign, particularly with regards to its appropriateness for paediatric populations in Nigeria. This paper reviews the oral health status of children in Nigeria, it evaluates the potential impact of the campaign for twice daily brushing, and provides suggestions for how best to address the critical oral health need of children in Nigeria.

To achieve the objectives of the discussion, a search was conducted for relevant literature using the following data bases; 'Pubmed, 'African Journal online' and 'Global health'. The search terms used were 'dental', caries', 'children', 'oral hygiene', 'tooth brushing frequency' and 'Nigeria'. Initial search retrieved over 2,063 articles, using the 'and'/'or' option reduced it to 153 articles. Review of the retrieved abstracts showed some articles were not relevant while there was some duplication. A total of 63 articles were downloaded, 17 of which were considered relevant for the present study. Where appropriate, the 'related articles' search tool was used to retrieve more relevant materials. In addition, the reference lists of all documents and articles retrieved in the previous search strategies were checked, to identify relevant materials. This retrieved a further 15 papers not earlier included. Figure 1 shows the literature search flowchart. Table 1 also gives details of the 32 articles retrieved for this review.

Materials included in this review comprise of articles that addressed the objectives of the study, including the studies that reported on the prevalence and severity of dental caries, and those that reported on dental service utilization. In order to ensure the validity and reliability of the information obtained, we examined the information for consistency and whenever possible, verified it by triangulating it with data in other documents. Information that could not be fully substantiated was excluded.

\section{Discussion}

A variety of dental conditions affect children in Nigeria. They include dental caries [10], periodontal diseases including acute necrotising ulcerative gingivitis [10], traumatic dental injuries [10] and HIV related dental problems [11]. However, dental caries is actually the main oral health concern in children in Nigeria and a problem that requires priority attention. This is because it is associated with significant morbidity [12-17], and negatively influences the quality of life in children.

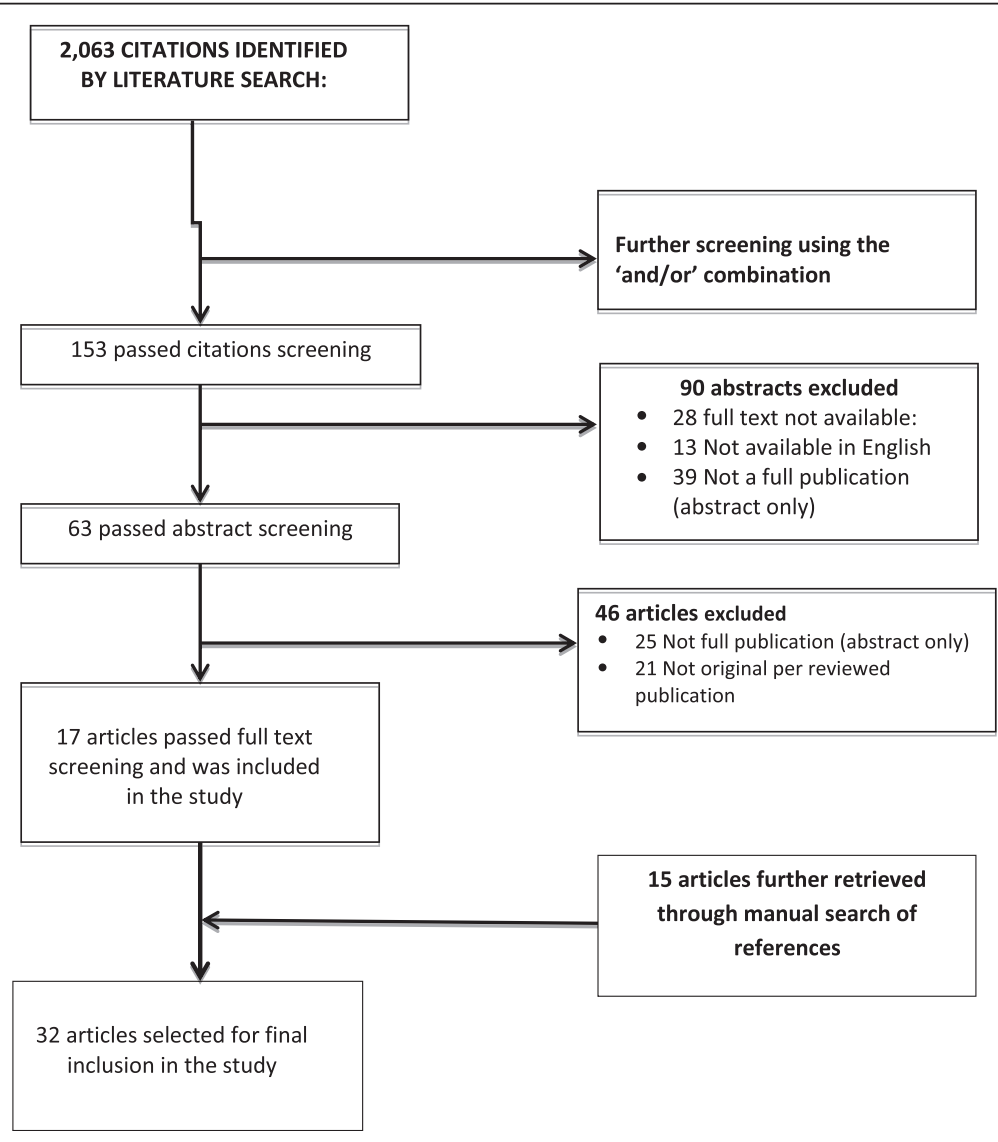

Figure 1 Literature search flowchart. 
Table 1 Articles discussing caries epidemiology in children in Nigeria

\begin{tabular}{|c|c|c|c|c|}
\hline S. no & Author [reference] & Target population & Age of children & Theme of the study \\
\hline 1 & Sofola et al. [4] & In-school & 2 years -12 years & Caries prevalence \\
\hline 2 & Folayan et al. [7] & In-school & 9 years -12 years & Oral health service utilisation \\
\hline 3 & Akpata [10] & NA & NA & Oral health status \\
\hline 4 & Adebola et al. [11] & Hospital based & $\leq 15$ years & Oral manifestation of HIV infection \\
\hline 5 & Oziegbe and Ezan [12] & In-school & 4 years -16 years & $\begin{array}{l}\text { Complication of caries in School } \\
\text { children in Nigeria }\end{array}$ \\
\hline 6 & Folayan et al. [13] & In-school & 2 years -12 years & Caries incidence in primary school children \\
\hline 7 & Chukumah et al. [14] & Hospital based & $\leq 16$ years & Tooth loss \\
\hline 8 & Folayan et al. [15] & Hospital based & $\leq 16$ years & Tooth loss \\
\hline 9 & Ashiwaju et al. [16] & Hospital based & $\leq 16$ years & Tooth loss \\
\hline 10 & Odia et al. [17] & Hospital based & $\leq 16$ years & Reasons for tooth extraction in children \\
\hline 11 & Folayan et al. [18] & NA & NA & Caries Epidemiology \\
\hline 12 & Sowole and Sote [20] & Preschool & 6 months -5 years & Early childhood caries \\
\hline 13 & Abiola et al. [21] & Preschool & 18 months -5 years & Caries and oral hygiene practices \\
\hline 14 & Adekoya-Sofowora et al. [22] & Preschool & 1-5years & Rampant caries prevalence \\
\hline 15 & Umesi-Koleosho et al. [23] & In-school & 11 years - 16 years & Caries trend \\
\hline 16 & Adeniyi et al. [24] & In-school & 5 years -16 years & Caries prevalence and pattern \\
\hline 17 & Okoye and Eknweme [25] & In-school & 11 years - 16 years & Caries prevalence \\
\hline 18 & Folayan et al. [26] & Hospital based & $\leq 16$ years & Risk factors for caries \\
\hline 19 & Udoye et al. [27] & In-school & 12 years - 15 years & Caries prevalence and pattern \\
\hline 20 & Adekoya-Sofowora et al. [28] & In-school & 12 years & Caries prevalence \\
\hline 21 & Giwa [29] & In-school & 12 years & Oral health status of children \\
\hline 22 & Folayan et al. [30] & Preschool & 6 months -5 years & Caries risk factor \\
\hline 23 & Folayan et al. [31] & Hospital based & 1 year - 16 years & Caries risk factor for children \\
\hline 24 & Folayan et al. [32] & In-school & 8 years -16 yeas & Preventive oral health practices \\
\hline 25 & Sowole et al. [34] & Preschool & 6 months -5 years & Dental caries and oral hygiene practices \\
\hline 26 & Folayan et al. [35] & Preschool & 6 months -5 years & Caries and infant feeding practice \\
\hline 27 & Adeniyi et al. [36] & Preschool & 18 months - 5 years & Oral health risk factors \\
\hline 28 & Esan et al. [38] & In-school & 2 and 20 years. Mean age: 9.5 yrs \pm 2.4 yrs. & Oral health status of primary school children \\
\hline 29 & Bamgboye and Akande [39] & In-school & 11-19 years & Oral health status of secondary school children \\
\hline 30 & Kolawole et al. [33] & In-school & Mean age: $12.63 \pm 1.06$ years & Oral hygiene status \\
\hline 31 & Ageblusi and Jeboda [40] & In-school & 12 year olds & Oral health status of 12 year old children \\
\hline 32 & Okolo et al. [45] & Community based & $1-7$ years & Oral hygiene and nutritional status \\
\hline
\end{tabular}

\section{The caries burden and profile of children in Nigeria}

The prevalence of caries in children in Nigeria is lower than what is observed in many developing countries. The prevalence ranges from between $11.2 \%$ and $48.0 \%$ : higher in urban than in rural areas, higher in Northern than in Southern Nigeria, and higher in primary than in permanent dentition [18]. The higher caries prevalence in Northern Nigeria has been attributed to the higher cariogenic diet and low manpower to address the oral health needs, relative to what obtains in Southern Nigeria [19]. The prevalence of early childhood caries (ECC) is one of the lowest globally, with prevalence ranging between $5.5 \%$ and $10.9 \%$ [20-22].

Ethnic differences in caries profile have also been reported [23,24]. The severity of caries is also comparatively lower than what is observed in many developing countries around the world, with the DMFT ranging between 0.02 and 0.85 in the permanent dentition, and dmft higher than 1.0 only reported in the primary dentition [18]. Caries incidence of 9.9 per 100 children has also been reported, with the relative risk of developing new caries significantly higher in those who already have 
it [13]. Unfortunately, the treatment of caries is low, with the proportion of children with untreated caries ranging between $77.2 \%$ and $98.6 \%$ in various communities in Nigeria [18].

Caries prevalence does not differ by sex [25] though it increases with age $[26,27]$. The association between socioeconomic status (SES) and caries prevalence is less clear, with a study showing that caries prevalence is higher in children from low SES [28], while others show there is no significant difference in caries prevalence by SES [21,29]. Folayan et al. [30] however showed that the odds of preschool children having caries increased by $23 \%$, as the socioeconomic status decreased.

Children from low socio-economic status however utilise oral health care services less than children from high and middle socio-economic status [31]. A child's birth rank is not associated with caries risk [31]. However, having older siblings with caries increases the risk of a child having caries [31].

The use of fluoride containing toothpaste in Southern Nigeria is also widespread [32,33]. Less than a third of school aged children consumed sugar less than once a day [32]. Only $7.8 \%$ of school aged children use a combination of caries risk prevention tools (consumption of refined carbohydrate once a day, continuous use of fluoridated toothpaste once a day or more, and restricted intake of refined carbohydrate) [32]. More older children and females use a combination of caries risk prevention tools [32]. The risk of caries increases with the frequency of daily consumption of sugar and with every score increase in oral hygiene index [25,34]; it also decreases with use of fluoridated toothpaste [24].

Other identified factors associated with the risk of caries among children in Nigeria include; infant feeding practices (children breastfed for more than 2 years have an increased risk for EEC) [35], maternal age (for every year increase in a mother's age, the odds of the child developing caries increases by one fold) [36] and maternal attitude to oral health (the child's risk of having caries is reduced by $15 \%$ with a unit increase in positive attitude of the mother) [34]. The residential location of the child also influences the form of caries risk the child is exposed to (children from urban areas area more likely to be breast fed on demand and at bedtime, while children from the rural area were more likely to be breast fed on schedule) [29].

Overall, the prevalence and severity of dental caries in children in Nigeria is lower than the 2000 World Health Organisation (WHO) reference standard. Untreated decayed teeth seem to be the main oral health concern in Nigerian children. The second concern is the higher prevalence of untreated dental caries and the relatively higher severity of caries in the primary dentition [4]. Third, risk factors for caries in the primary dentition include maternal factors that if otherwise modified, can improve the oral health behaviour of children.

\section{Oral hygiene and caries risk in children in Nigeria}

Mathiesen et al. [37] showed that there were significantly fewer carious lesions and filled aproximal surfaces in Norwegian children with good oral hygiene compared with children with poor oral hygiene. The results of studies conducted in Nigeria equally corroborate this finding $[19,38]$. While the oral hygiene status has been shown to be an important correlate for caries occurrence, no study conducted in Nigeria till date has been able to demonstrate a relationship between frequency of tooth brushing and caries prevalence [38-40]. There were non-statistical differences in the oral hygiene scores of children who brush once a day compared with those who brush twice a day [33]. The importance of tooth brushing efficacy over tooth brushing frequency in reducing the risk for caries had been earlier highlighted [41,42]. Honkala et al. [41] however noted that the amount of time spent brushing is more closely related to effectiveness of plaque removal than frequency of tooth brushing. Studies show that the practice of twice daily tooth brushing $[32,39]$ and the use of dental floss by pupils in Nigeria are low [32].

Evidence to support the association between caries prevalence and severity, and tooth brushing frequency is poor [42]. There is also no significant difference in the caries profile of children in Nigeria who brush once a day and those who brush more than once a day [24]. There is therefore no justification for a campaign promoting twice daily brushing as a caries prevention strategy for children in Nigeria.

However the increased frequency of tooth brushing increases the availability of fluoride in the mouth [42]. There are global evidences to demonstrate that fluoride reduces the risk for caries [43,44]. The risk for caries had also been demonstrated to be reduced in children in Nigeria, who use fluoridated toothpaste [24]. Thus, where and when feasible, campaigns should promote the use of fluoride containing toothpaste by children in Nigeria. Twice daily tooth brushing should be a mechanism to promote increased availability of fluoride in the oral cavity. The promotion of twice daily tooth brushing habits in children also helps to promote the establishment of a habit that helps prevent the development of periodontal diseases [42] in later years.

\section{Is there any relationship between oral hygiene and periodontal disease in children}

In Nigeria, research reports indicate that although oral cleanliness in children is suboptimal with majority of adolescents having fair oral hygiene $[40,45]$, the prevalence of gingivitis is however, low [40]. Clearly, gingival 
inflammation is a necessary but not sufficient prerequisite for periodontitis. Periodontitis is often a manifestation of systemic disease when it occurs in children. Chronic periodontitis has its incipient beginning in adolescence, but is more prevalent among adults. For the most part, surveys indicated that loss of periodontal attachment and supporting bone is relatively uncommon in the young. The incidence is however higher in adolescents aged 12 to 17 years, when compared to children aged five to 11 years [46-49].

The low prevalence of periodontitis in children is due to a number of known factors. First, there is greater anabolic than catabolic activity in children [50] thus making the periodontium more resistant to breakdown. In the unlikely event of breakdown, anabolic activity may enhance concurrent repair. Second, the oral flora is different in children. The aetiological agents of periodontitis - spirochaetes, bacteriodes melaninogenicus and Porphyromonas gingivalis are established late in the oral flora of children [51]. Third, plaque in children has lower irritation potential; oral hygiene can be withheld in preschool children for 27 days with no consequences unlike in adults where inflammatory changes become obvious by the $3^{\text {rd }}$ day [52]. For children in whom the risk for periodontal diseases is low, conducting a major public health campaign to promote twice daily tooth brushing in a bid to reduce periodontal disease in children would be considered inefficient use of resources [53].

\section{Relationship between severe periodontal disease and heart disease}

Evidences suggest that dental health, in particular periodontal disease, may be a significant risk factor for coronary heart disease and further coronary events [54]. The INVEST study however demonstrated equivocally the link between periodontitis and carotid artery plague [55]. The study noted that tooth loss was a marker of past periodontal disease in the study population, and was related to subclinical atherosclerosis thereby providing a potential pathway for a relationship with clinical events. There was however no conclusive causal inferential relationship between any specific heart condition and periodontitis. Rather, there was evidence to suggest increased risk of coronary heart diseases arising from severe periodontal diseases in adults above 40 years of age, particularly men. The American Heart Association also published a report stating that there is no evidence that periodontal disease causes cardiovascular disease, nor is there proof that taking care of your gums will prevent heart disease [56].

Advanced forms of periodontal disease are rare in children though nearly all children and adolescents have gingivitis [47]. The potential risk of coronary heart disease, if there truly is one, is therefore not a concern in childhood. While it may be argued that good habits need to be formed in childhood, there is currently little evidence to substantiate that twice daily tooth brushing significantly reduces plaque formation in children in Nigeria, and therefore, the risk for coronary heart disease that may arise from cumulative events from childhood. The international recommendation for oral health prevention and prophylaxis is daily tooth brushing, with affordable fluoride toothpaste [57].

\section{What is the evidence for a responsive oral health campaign among children in Nigeria}

While the comparatively low caries prevalence and severity in children in Nigeria is impressive, emerging evidence shows that despite school based oral health education programmes, caries incidence in the primary dentition continued to increase, while it decreased in the permanent dentition [4]. Oral health campaigns and programmes on children need to focus on how to reduce caries incidence in the primary dentition, while consolidating the gains made with the permanent dentition. The cumulative gain observed with the National data showing a general decrease in caries prevalence in the country over the last two decades [18], may have actually resulted from a camouflage produced by the decreasing caries incidence in the permanent dentition.

Little is however known or understood about 'why and 'how' the prevalence and severity of dental caries in the permanent dentition had remained low. The widespread public access to fluoridated toothpaste may have played a role in this observed phenomenon [32]. Regular exposure to fluoride through the use of dentifrices when brushing the teeth, reduces the risk of caries [42,58]. The reason for high caries prevalence in the primary dentition in Nigerian children remains unclear. One possibility is that tooth cleansing and the use of fluoridated toothpastes start late in these children. The efficacy of the use of fluoridated toothpaste in the reduction of caries in primary dentition has only been established in a single clinical study [59], while other reviews substantiate the finding $[44,60]$. It is important to generate the needed scientific evidence to establish how the gains with caries control in Nigeria were achieved, and identify the challenges faced with caries control in the primary dentition. This will help with the formulation of evidence-based caries control policies and programmes in Nigeria.

What remains clear however is that the number of untreated caries is unacceptably high, suggesting the existence of barriers to utilisation of dental care for children in Nigeria. Efforts need to be directed at addressing this unmet need. There are several publications in Nigerian literature on oral health promotion in children using the school visit approach [23,26,61-63]. School screening programmes and referral to dental clinics or 
hospitals for appropriate care, seems not to have been highly successful in improving the uptake of caries management services $[4,7]$.

\section{What should be the focus of the caries management programme for children in Nigeria?}

Anecdotal evidence suggests that many of these children do not report to the clinic for treatment, following referrals from school health programmes. It may therefore be more beneficial to include caries treatment strategies in school-based programmes for Nigerian children. Such school based programmes should explore the feasibility of including atraumatic tooth restorative programmes as components of school oral health programmes. Atraumatic tooth restorations have been used successfully in school based programmes in other parts of the world $[64,65]$. The introduction of atraumatic tooth restoration into school based oral health programmes would need to be piloted before being scaled up, so that logistic, financial and administrative challenges to programme implementation can be addressed and resolved, prior to nationwide implementation. The National Oral Health Policy [66] has highlighted the importance and role of atraumatic tooth restoration in caries management. Some of the cost associated with the implementation of a school based caries management programme could however be absorbed by the National Health Insurance Scheme (NHIS). The NHIS presently subsidises costs for restorative treatment, but does not subsidise costs for scaling and polishing [67].

A national caries prevention programme that is completely dependent on school based oral health programmes would however leave out a substantial number of children. First, only $60 \%$ of primary school aged children are actually in school [68]. Second, a majority of preschool children, who otherwise may be affected by early childhood caries, would not have been enrolled in schools, and would therefore not be reached by the caries prevention programme. In view of this limitation with school based programmes, Nigeria may need to complement her school based oral health programmes for children with programmes that give access to children resident within communities. Community based oral health programmes have helped increase the access of children in underserved communities, to oral health care programmes [69].

Low dental service utilisation may also arise from social and cultural norms. Poor hospital attendance is associated with cultural norms that associate hospital visits with only ill health. This cultural perception may have also deterred people from utilising hospital based oral health services, instead they prefer visiting chemists for dental care services [70,71]. Also, there are socioeconomic challenges associated with dental service utilisation: pupils living with single mothers or who had no parents, were less likely to utilise dental clinics [72]. Therefore, efforts may need to be focused on addressing those structural problems that impede access of children to dental care services. Access to dental care service is important, as professional tooth cleaning at least once every year, may inhibit caries on all tooth surfaces. Self-performed oral hygiene effectively prevents mainly free smooth surface caries and caries on the front teeth [73].

Caries treatment programmes still need to be complemented with public education programmes. Public education programmes need to emphasise caries prevention, by promoting effective tooth brushing using fluoride containing toothpaste. What we propose is a change in the messages provided on oral health care for children, during public oral health campaigns and education, in Nigeria. Messages for children should facilitate the utilisation of dental care services, for both preventive and prompt management of oral diseases, and promote the use of fluoride containing dentifrices for caries prevention.

\section{Summary}

Allocation of public health resources should be based, where feasible, on objective assessment of health status, burden of disease, their preventability and related cost [74]. This ensures efficient use of the limited financial and human resources. We however do not have enough evidence to suggest that twice daily brushing per se, would make any significant impact on caries prevention for children in Nigeria. Twice daily tooth brushing using fluoridated toothpastes would, however, facilitate increased exposure of the oral cavity to fluoride, and make an impact on caries prevention. Mobilising children with caries to receive dental treatment remains the current challenge, and a major oral health need that should be addressed. Children focused oral health campaigns in Nigeria should therefore promote improved uptake of dental services, and access to dental care providers.

\section{Competing interest}

We declare that the authors have no competing interest.

\section{Authors' contributions}

MOF initiated the idea for the manuscript, wrote the initial framework, and edited the manuscript. AAA, NO, NMC, AOE, OOS and $O O O$ assisted in the writing of the manuscript, including identifying the needed literature. AAA wrote the methodology section while NO helped with the extensive literature search. MOF and AAA supervised and edited the manuscript and all authors read and approved the final manuscript.

\section{Acknowledgement}

We acknowledge the useful suggestions and critical editorials made by Dr Ola Dennis.

\section{Author details}

${ }^{1}$ Department of Child Dental Health, Obafemi Awolowo University, lle-lfe, Nigeria. ${ }^{2}$ Department of Child Dental Health, Obafemi Awolowo University Teaching Hospitals Complex, lle-lfe, Nigeria. ${ }^{3}$ Paediatric Dentistry Working Group, Ile-Ife, Nigeria. ${ }^{4}$ Department of Preventive Dentistry Lagos State University College of Medicine, Lagos, Nigeria. ${ }^{5}$ Department of Preventive and Community Dentistry, University of Lagos, Lagos, Nigeria. ${ }^{6}$ Department of Preventive and Community Dentistry, Obafemi Awolowo University Teaching Hospitals 
Complex, lle-lfe, Nigeria. 'Department of Child Dental Health, University of Lagos, Lagos, Nigeria.

Received: 25 November 2013 Accepted: 10 October 2014 Published: 21 October 2014

\section{References}

1. Johnsen DC: The preschool "passage": an overview of dental health. Dent Clin N Am 1995, 39:695-707.

2. Blinkhorn AS: Promoting dietary changes in order to control dental caries. Dent Health 1991, 29:3-6.

3. Christensen P: The health-promoting family: a conceptual framework for future research. Soc Sci Med 2004, 59:377.

4. Sofola OO, Folayan MO, Oginni AB: Changes in the prevalence of dental caries in primary school children in Lagos State, Nigeria. J Clin Pract 2014, 17:127-133

5. Coughlin SS: Ethical issues in epidemiologic research and public health practice. Emerg Themes Epidemiol 2006, 3:16.

6. Quaid KA: Psychological and ethical considerations in screening for disease. Am J Cardiol 1993, 72:64D-67D.

7. Folayan MO, Ozeigbe E, Oyedele T, Ola D: Factors limiting dental service utilization by pupils in lle-lfe, Nigeria. Nig J Health Sci 2013, 3:18-23.

8. Montebugnoli L, Servidio D, Miaton RA, Prati C, Tricoci P, Melloni C, Melandri G: Periodontal health improves systemic inflammatory and haemostatic status in subjects with coronary heart disease. J Clin Periodontol 2005, 32:188-192.

9. Dhadse P, Gattani D, Mishra R: The link between periodontal disease and cardiovascular disease: How far we have come in the last two decades. J Indian Soc Periodontol 2010, 14:148-154.

10. Akpata ES: Oral health in Nigeria. Int Dent J 2004, 54:341-366.

11. Adebola AR, Adeleke SI, Mukhtar M, Osunde OD, Akhiwu BI, Ladeinde A: Oral manifestation of HIV/AIDS infections in paediatric Nigerian patients. Nig Med J 2012, 53:150-154.

12. Oziegbe EO, Esan TA: Prevalence and clinical consequences of untreated dental caries using PUFA index in suburban Nigerian school children. Eur Arch Paediatr Dent 2013, 14:227-231.

13. Folayan $\mathrm{MO}$, Sofola $\mathrm{OO}$, Oginni $\mathrm{AB}$ : Caries incidence in a cohort of primary school students in Lagos State, Nigeria followed up for over a 3 years period. Eur Arch Paediatr Dent 2012, 13:312-318.

14. Chukwumah N, Azodo C, Orikpete E: Analysis of tooth mortality among nigerian children in a tertiary hospital setting. Ann Med Health Sci Res 2014, 4:345-349.

15. Folayan MO, Otuyemi OD, Esan OO, Adeleke AO, Adedigba MA: Pattern of dental extraction in children in a Nigerian Tertiary Hospital. J Contemp Dent Pract 2005, 6:80-90.

16. Ashiwaju MO, Folayan MO, Sote EO, Isikwe MC: Pattern of tooth extraction in children attending tertiary health care centers in Nigeria: a prospective study. J Clin Pediatr Dent 2011, 36:107-110.

17. Odai CD, Azodo CC, Ezeja EB, Obuekwe ON: Reasons for exodontia in rural Nigerian children. Odontostomatol Trop 2010, 33:19-24.

18. Folayan MO, Chukumah NM, Onyejaka N, Adeniyi A, Olatosi O: Appraisal of the national response to caries epidemic in children in Nigeria. BMC Oral Health 2014, 14:76

19. Henshaw NE, Adenubi JO: The increase in dental disease in the northern states of Nigeria and its manpower implications. J Dent 1975, 3:243-250.

20. Sowole CA, Sote EO: Early childhood caries: experience in Nigerian children in Lagos. Niger Postgrad Med J 2007, 14:314-318.

21. Abiola AA, Eyitope OO, Sonny OJ, Oyinkan OS: Dental caries occurrence and associated oral hygiene practices among rural and urban Nigerian pre-school children. J Dent Oral Hyg 2009, 1:64-70.

22. Adekoya-Sofowora CA, Nasir WO, Ola D: Rampant caries experience in a Nigerian teaching hospital population. Niger Postgrad Med J 2006, 13:89-94.

23. Umesi-Koleosho DC, Ayanbadejo P, Oremosu OA: Dental caries trend among adolescents in Lagos South-West Nigeria. West Afr J Med 2007, 26:201-205.

24. Adeniyi AA, Agbaje MO, Onigbinde OO, Ashiwaju O, Ogunbanjo O, Orebanjo O, Adegbonmire O, Adegbite K: Prevalence and pattern of dental caries among a sample of Nigerian public primary school children. Oral Health Prev Dent 2012, 10:267-274.

25. Okoye LO, Ekwueme OC: Prevalence of dental caries in a Nigerian rural community: A preliminary local survey. Ann Med Health Sci Res 2011, 1:187-195.
26. Folayan MO, Sowole A, Kola-Jebutu A: Risk factors for caries in Nigerian children. J Clin Paediatr Dentist 2008, 32:171-175.

27. Udoye C, Aguwa E, Chikezie R, Ezeokenwa M, Jerry-Oji O, Okpaji C: Prevalence and distribution of caries in the 12-15 year urban school children in Enugu, Nigeria. Internet J Dental Sci 2009, 7. doi:10.5580/22a32009.

28. Adekoya-Sofowora CA, Nasir WO, Oginni AO, Taiwo M: Dental caries in 12-year-old suburban Nigerian school children. Afr Health Sci 2006, 6:145-150.

29. Giwa AA: Oral health status of 12 years old school children in private and public schools in Lagos State, An unpublished dissertation submitted to the Faculty of Surgery of the National Postgraduate Medical College of Nigeria in partial fulfillment of the award of the Fellowship of the College. 2005.

30. Folayan MO, Sowole CA, Owotade FJ: Residential location and caries risk of preschool children in Lagos, Nigeria. Afr J Med Med Sci 2012, 41:43-48.

31. Folayan MO, Owotade FJ, Ozeigbe E, Fadeyibi R: Effect of birth rank on the caries experience of children from a suburban population in Nigeria. J Dent Oral Hygiene 2010, 2:27-30.

32. Folayan MO, Khami MR, Popoola OO, Onyejaka N, Adeyemo YI: Preventive oral health practices of school pupils in Southern Nigeria. BMC Oral Health 2014, 14:83.

33. Kolawole KA, Oziegbe EO, Bamise CT: Oral hygiene measures and the periodontal status of school children. Int J Dent Hyg 2011, 9:143-148.

34. Sowole A, Sote E, Folayan M: Dental caries pattern and predisposing oral hygiene related factors in Nigerian preschool children. Eur Arch Paediatr Dent 2007, 8:206-210.

35. Folayan MO, Sowole CA, Owotade FJ, Sote E: Impact of infant feeding practices on caries experience of preschool children. J Clin Pediatr Dent 2010, 34:297-301.

36. Adeniyi $\mathrm{OO}$, Jeboda SO, Ogunbodede EO, Folayan MO: Do maternal factors influence the dental health status of Nigerian preschool children. Int $J$ Paediatr Dent 2009, 19:448-454.

37. Mathiesen AT, Øgaard B, Rølia G: Oral hygiene as a variable in dental caries experience in 14-year-olds exposed to fluoride. Caries Res 1996, 30:29-33.

38. Esan A, Ukpong MO, Egbetade G, Oyedele T, Adeosun A: Oral health status of primary school students in Ife Central Local Government Area, Osun State Nigeria. International Association of Dental Research, AMER. Abuja: Abuja; 2011:28-30.

39. Bamgboye $\mathrm{O}$, Akande TM: Oral hygiene status of students in selected secondary schools in Osogbo, Nigeria. Nig Med Pract 2007, 51:71-75.

40. Agbelusi GA, Jeboda SO: Oral health status of 12 year old Nigerian children. WAJM 2006, 25:195-198.

41. Honkala E, Nyyssönen V, Knuuttila M, Markkanen H: Effectiveness of children's habitual toothbrushing. J Clin Periodontol 1986, 13:81-85.

42. Davies RM, Davies GM, Ellwood RP: Prevention. Part 4: Tooth brushing: what advice should be given to patients. Br Dent J 2003, 195:135-141.

43. Ammari AB, Bloch-Zupan A, Ashley PF: Systematic review of studies comparing the anti-caries efficacy of children's toothpaste containing $600 \mathrm{ppm}$ of fluoride or less with high fluoride toothpastes of 1,000 ppm or above. Caries Res 2003, 37:85-92.

44. Twetman S, Axelsson S, Dahlgren H, Holm AK, Kallestal C, Lagerlöf F, Lingström P, Mejàre I, Nordenram G, Norlund A, Petersson LG, Söder B: Caries-preventive effect of fluoride toothpaste: a systematic review. Acta Odontol Scand 2003, 61:347-355.

45. Okolo S, Chukwu G, Egbuonu I, Ezeogu F, Onwuanaku C, Adeleke O, Hassan A, Ngoe-Nesoah A: Oral hygiene and nutritional status of children aged 1-7 years in a rural community. Ghana Med J 2006, 40:22-25

46. Wei SJY, Yang S, Barmes DE: Needs and implementation of preventive dentistry in China. Community Dent Oral Epidemiol 1986, 14:19-23.

47. Wolfe MD, Carlos JP: Periodontal disease in adolescents: Epidemiologic findings in Navajo Indians. Community Dent Oral Epidemiol 1987, 15:33-40.

48. Durward CS, Wright FA: The dental health of IndoChinese and Australian-born adolescents. Austr Dent J 1989, 34:233-239.

49. Miyazaki H, Hanada N, Andoh MI, Yamashita Y, Saito T, Sogame A, Goto K, Shirahama R, Takehara T: Periodontal disease prevalence in different age groups in Japan as assessed according to the CPITN. Community Dent Oral Epidemiol 1989, 17:71-74.

50. Antranik: Anabolic and catabolic reactions. http://antranik.org/anabolicand-catabolic-reactions/, Accessed 24 $4^{\text {th }}$ September, 2014.

51. Mättö J, Saarela M, Alaluusua S, Oja V, Jousimies-Somer H, Asikainen S: Detection of Porphyromonas gingivalis from Saliva by PCR by Using a Simple Sample-Processing Method. J Clin Microbiol 1998, 36:157-160.

52. Ukpong M: Oral soft tissue lesions, Lecture notes for clinical 1 students of the Obafemi Awolowo University, Ile-lfe; 2005. 
53. National Oral Health Promotion Clearing House: Oral health messages for the Australian public. Findings of a national consensus workshop. Aust Dent J 2011, 56:331-335.

54. Seymour RA, Steele JG: Is there a link between periodontal disease and coronary heart disease? Br Dent J 1998, 184:33-38.

55. Desvarieux M, Demmer RT, Rundek T, Boden-Albala B, Jacobs DR, Papapanou PN, Sacco RL, Oral Infections and Vascular Disease Epidemiology Study(INVEST): Relationship between periodontal disease, tooth loss, and carotid artery plaque: the oral infections and vascular disease epidemiology study (INVEST). Stroke 2003, 34:2120-2125.

56. Lockhart PB, Papapanou PN, Osinbowale O, Trevisan M, Levison ME, Taubert KA, Newburger JW, Gornik HL, Gewitz MH, Wilson WR, Smith SC Jr, Baddour LM, American Heart Association Rheumatic Fever, Endocarditis, and Kawasaki Disease Committee of the Council on Cardiovascular Disease in the Young, Council on Epidemiology and Prevention, Council on Peripheral Vascular Disease, and Council on Clinical Cardiology: Periodontal disease and atherosclerotic vascular disease: does the evidence Ssupport an independent association? A scientific statement from the American Heart Association. Circulation 2012, 125:2520-2544.

57. EU Public health programme project: Global report on the public health status in the European Union: towards a healthier Europe. Full report Available at: http://euglorehcd.eulogos.it/IXT/_EXT-REP/_P6A.HTM. Accessed on $17^{\text {th }}$ July, 2012.

58. Marinho VCC, Higgins JPT, Sheiham A, Logan S: Fluoride toothpastes for preventing dental caries in children and adolescents (Cochrane Review). In The Cochrane Library, Issue 1. Oxford: Update Software; 2003.

59. Cahen PM, Frank RM, Turlot JC, Jung MT: Comparative unsupervised clinical trial on caries inhibition effect of monofluorophosphate and amine fluoride dentifrices after 3 years in Strasbourg, France. Community Dent Oral Epidemiol 1982, 10:238-241.

60. Dos Santos AP, Nadanovsky P, de Oliveira BH: A systematic review and meta-analysis of the effects of fluoride toothpastes on the prevention of dental caries in the primary dentition of preschool children. Community Dent Oral Epidemiol 2012, doi:10.1111/j.1600-0528.2012.00708.x.

61. Okeigbemen SA: The prevalence of dental caries among 12 to 15-year-old school children in Nigeria: report of a local survey and campaign. Oral Health Prev Dent 2004, 2:27-31.

62. Denloye O, Ajayi D, Bankole O: A study of dental caries prevalence in 12-14 year old school children in Ibadan, Nigeria. Pediatric Dental J 2005, 15:147-151.

63. Okoye LO, Chukweneke FN, Akaji EA, Folaranmi N: Caries experience among school children in Enugu, Nigeria. J College Med 2010, 14:17-23.

64. Frencken JE, Van't Hof MA, Taifour D, Al-Zaher I: Effectiveness of ART and traditional amalgam approach in restoring single-surface cavities in posterior teeth of permanent dentitions in school children after 6.3 years. Community Dent Oral Epidemiol 2007, 35:207-214.

65. Frencken JE, Makoni F, Sithole WD, Hackenitz E: Three-year survival of one-surface ART restorations and glass-ionomer sealants in a school oral healthprogramme in Zimbabwe. Caries Res 1998, 32:119-126.

66. Federal Ministry of Health: National Oral Health Policy, Abuja, Nigeria. 2012.

67. Adeniyi AA, Sofola OO, Kalliecharan RV: An appraisal of the oral health care system in Nigeria. Int Dent J 2012, 62:292-300.

68. Nigeria Education Fact Sheet. 2013. Available at: http://photos.state.gov/ libraries/nigeria/487468/pdfs/JanuaryEducationFactSheet.pdf Accessed $15^{\text {th }}$ May 2013.

69. Diamond R, Litwak E, Marshall S, Diamond A: Implementing a communitybased oral health care program: lessons learned. J Public Health Dent 2003, 63:240-243.

70. Omolase $\mathrm{CO}$, Adeleke OE, Afolabi AO, Afolabi OT: Self medication amongst general outpatients in a Nigerian community hospital. Ann Ibadan Postgrad Med 2007, 5:64-67.

71. Adedapo HA, Lawal AO, Adisa AO, Adeyemi BF: Non-doctor consultations and self-medication practices in patients seen at a tertiary dental center in Ibadan. Indian J Dental Res 2011, 22:795-798.
72. Ola D, Gamboa ABO, Folayan MO, Marcenes W: Family structure, socio-economic position and oral health services utilisation in Nigerian senior secondary school pupils. J Pub Health Dent 2012, Sep 13. doi: 10.1111/j.1752-7325.2012.00362.x.

73. Bellini HT, Arneberg P, von der Fehr FR: Oral hygiene and caries. A review. Acta Odontol Scand 1981, 39:257-265.

74. Thacker SB, Stroup DF, Carande-Kulis V, Marks JS, Roy K, Gerberding JL: Measuring the public's health. Public Health Rep 2006, 121:14-22.

doi:10.1186/1472-6831-14-128

Cite this article as: Folayan et al:: Programme guidelines for promoting good oral health for children in Nigeria: a position paper. BMC Oral Health 2014 14:128.

\section{Submit your next manuscript to BioMed Central and take full advantage of:}

- Convenient online submission

- Thorough peer review

- No space constraints or color figure charges

- Immediate publication on acceptance

- Inclusion in PubMed, CAS, Scopus and Google Scholar

- Research which is freely available for redistribution

Submit your manuscript at www.biomedcentral.com/submit
C Biomed Central 